\title{
Advanced Microstructural Characterization of Alloy 600 Intergranular Oxidation
}

\author{
G. Bertali*, F. Scenini, M. G. Burke. \\ Material Performance Centre, The University of Manchester, Manchester (UK) \\ *corresponding author: giacomo.bertali@ postgrad.manchester.ac.uk; +447462777504
}

\begin{abstract}
Oxidation of solution-annealed Alloy 600 has been performed in a hydrogenated steam environment, which is considered to simulate PWR primary water exposure. FIB and analytical TEM characterization, coupled with detailed SEM analyses, provided unequivocal evidence of localized grain boundary migration and intergranular oxide penetrations. These localized migrations were associated with pronounced $\mathrm{Cr}$ and $\mathrm{Fe}$ depletions, highlighting the role of the grain boundaries for $\mathrm{Cr}$ diffusion for intergranular oxidation. These findings are discussed in relation to the early stages of intergranular oxidation, diffusion-induced grain boundary migration and subsequent SCC initiation.
\end{abstract}

Key words: Alloy 600 , preferential intergranular oxidation, grain boundary migration, microstructure, AEM.

\section{Introduction}

The susceptibility of Alloy 600 to intergranular stress corrosion cracking (IGSCC) in pressurised water reactor (PWR) primary water environment is well-known. Amongst all the models proposed, the internal oxidation model by Scott and Le Calvar in 1992 [1] appears to be the most comprehensive. Several laboratories reported a marked dependency between 
crack growth rate and electrochemical potential for Alloy 600 exposed in PWR simulated primary water with the highest susceptibility in the region of the $\mathrm{Ni} / \mathrm{NiO}$ equilibrium potential [2,3], where internal oxidation is more likely to occur. This model has evolved since it was first formulated, as has its role in crack nucleation and growth. However, the key parameters responsible for the general and localised "internal" oxidation susceptibility of Alloy 600 in PWR primary environment are still unclear and require elucidation to develop a mechanistic understanding of the phenomena and to assess their relative importance.

One of the major concerns regarding the internal oxidation mechanism is that the $\mathrm{O}$ and $\mathrm{Cr}$ diffusion coefficients in $\mathrm{Ni}$ that have been extrapolated from much higher temperature data [4-6] are four orders of magnitude lower than the one required to explain the experimentallyobserved IGSCC rate in a PWR primary water environment [7]. However, the extrapolated diffusion coefficients for $\mathrm{Cr}$ and $\mathrm{O}$ do not agree with the experimentally-measured diffusion coefficients in PWR conditions as reported by Fujii et al. and Lozano-Perez et al. [8,9]. Based on these observations, the only possible explanation that can account for the discrepancy between extrapolated and measured diffusion coefficients is an enhanced $\mathrm{Cr}$ and O diffusivity at the lower PWR operating temperatures. In order to explain these phenomena, advanced characterization techniques have been employed by several researchers to study the intergranular oxide formed on Alloy 600 in simulated PWR primary water [9-14]. However, the factors responsible for the occurrence of preferential intergranular oxidation and enhanced $\mathrm{O}$ and $\mathrm{Cr}$ diffusivity are still unclear and under debate.

Recently, several independent observations of grain boundary (GB) migration have been reported for Alloy 600 and Alloy 690 in association with intergranular oxide penetrations [11,15,17]. A very localised ( $9 \mathrm{~nm})$ Cr-depleted grain boundary region was detected using Atom Probe Tomography (APT) in an Alloy 600 specimen exposed to PWR water at $320^{\circ} \mathrm{C}$ 
that contained an intergranular oxide [11]. The presence of a well-defined, asymmetric Crand Fe-depleted/Ni-rich region adjacent to a grain boundary immediately beneath the surface of an oxidised Alloy 600 specimen was also observed by Bertali et al. and Lindsay et al. $[17,18]$. However, it was not possible to conclusively demonstrate that the boundaries had migrated in these studies.

The aim of this study was to investigate the initial stages of preferential intergranular oxidation with emphasis on the characterisation of localised grain boundary migration and its role on the intergranular oxidation susceptibility of Alloy 600. The oxidation studies were performed at $480{ }^{\circ} \mathrm{C}$ in low pressure $\mathrm{H}_{2}$-steam environment, which is considered to simulate PWR primary water environment. In fact, it has been shown by Economy et al. [19] that Alloy 600 IGSCC behaviour in steam at $400{ }^{\circ} \mathrm{C}$ does not involve changes in mechanism from $320{ }^{\circ} \mathrm{C}$ PWR primary water, and it is therefore assumed that the mechanism will be the same at $480^{\circ} \mathrm{C}$. The present paper reports a detailed microstructural investigation using high resolution field emission gun (FEG) scanning electron microscopy (SEM) and advanced analytical transmission electron microscopy (ATEM) of solution-annealed Alloy 600 exposed to $\mathrm{H}_{2}$-steam at $480^{\circ} \mathrm{C}$, and demonstrates that grain boundary migration occurs during the oxidation process.

\section{Experimental procedures}

\section{$\underline{\text { Material and sample preparation }}$}

The Alloy 600 used in this study was provided from B\&W Tubular Products Division via Westinghouse. The composition of this material is reported in Table 1. This material, originally provided in a low-temperature mill-annealed condition, was subsequently solutionannealed (SA) and water-quenched in order to minimize the extent of intergranular carbide 
precipitation and produce a coarse-grained recrystallized microstructure to facilitate the mechanistic interpretation of the oxidation behaviour. The material was heat-treated in air in a preheated furnace at $1100^{\circ} \mathrm{C}$ for 30 minutes and then water-quenched to room temperature within 10 seconds. The SA Alloy 600 was then sectioned to remove the near-surface material (several millimetres in thickness), and the oxidation coupons were then sliced so that the surfaces of interest were located several millimetres away from the original heat-treated (oxidized) surface. In this way any pre-oxidation that occurred during the heat-treatment would not affect the subsequent oxidation experiments.

Rectangular oxidation coupons $\left(20 \times 15 \times 1 \mathrm{~mm}^{3}\right)$ of SA Alloy 600 were cut from bulk material using a diamond edge-cutting disk. The coupons were metallographically polished with 3 $\mu \mathrm{m}$ diamond paste. In order to remove any superficial deformation induced by mechanical polishing and to obtain a surface free from any residual stress, one surface was further polished with a colloidal silica polishing suspension $(60 \mathrm{~nm})$. The surface after colloidal silica polishing is representative of the bulk material (free of surface deformation). After polishing, the samples were ultrasonically cleaned in deionized water to remove any colloidal silica contamination and then dried in hot air.

\section{Hydrogenated-steam oxidation system}

The oxidation experiments were conducted in a low-pressure $\mathrm{H}_{2}$-steam environment at temperatures up to $480{ }^{\circ} \mathrm{C}$ for different exposure times at a water flow rate of $1.8 \mathrm{~mL} / \mathrm{min}$ and a steam-to- $\mathrm{H}_{2}$ ratio of 62.16 , which correspond to an oxygen partial pressure of $2.34 \times 10^{-}$ ${ }^{24}$ atm. This system had previously been employed in past oxidation experiments on Nibased alloys [16-18,20,21], and it had been shown to accelerate the oxidation of the alloys whilst maintaining the appropriate thermodynamic conditions with respect to the $\mathrm{Ni} / \mathrm{NiO}$ transition that are relevant to those conditions to PWR primary water at operating 
temperatures. Therefore, the main reason for the selection of this system was the ability to perform oxidation tests relevant to the PWR environment in a relatively rapid and simple manner. The oxidation system used for the experiments allowed the oxygen partial pressure over the $\mathrm{Ni} / \mathrm{NiO}$ transition [16] to be set by adjusting the hydrogen and steam flow rate. Additional details concerning the operation of the system are provided in reference $[16,20]$.

A total of 4 oxidation experiments were conducted, and the experimental conditions for each test as well as the test purpose are reported in Table 2.

\section{Microstructural characterization}

The specimens were characterized prior to and after oxidation using a variety of complementary microstructural analysis techniques including FEG-SEM, focused ion beam (FIB) microscopy, and analytical TEM (AEM). The as-polished pre-exposure and postexposure (oxidized) samples surfaces were evaluated using a Zeiss Ultra 55 FEG-SEM equipped with an Oxford Instruments Energy Dispersive X-ray (EDX) INCA analysis system. An FEI Quanta 3D Dual Beam FIB/SEM was used for the preparation of crosssection specimens for subsequent analysis. The cross-section specimens of as-polished and oxidized Alloy 600 coupons were initially analysed using an FEI Magellan 400 XHR FEGSEM and an Zeiss Ultra 55 FEG-SEM using the Inlens detector and a BSE detector at high $(20 \mathrm{kV})$ and low accelerating voltage $(3-5 \mathrm{kV})$.

The cross-section specimens of the oxidised coupons containing grain boundaries were extracted from the bulk coupons using the TEM lift-out technique, mounted on grids, and subsequently thinned using the FIB. This technique has been widely used for TEM sample preparation [22-24]. In order to characterise the general Alloy 600 microstructure, including 
type and extent of precipitation, conventional TEM specimens were prepared from $3.0 \mathrm{~mm}$ diameter 100 micron thick disc samples obtained from the solution-annealed and waterquenched Alloy 600. These were electropolished in $20 \% \mathrm{HClO}_{4}-80 \% \mathrm{CH}_{3} \mathrm{OH}$ at $-33^{\circ} \mathrm{C}$ using a Struers Tenupol 5 equipped with a Jubalo closed cycle refrigeration system.

Detailed AEM characterization of all TEM specimens was performed using an FEI Tecnai F30 $300 \mathrm{kV}$ FEG-AEM equipped with an Oxford Instruments X-max80 Silicon Drift Detector (SDD) and AZTEC analysis system. Discrete EDX "spot" analyses were performed to document the composition at various locations along the high-angle grain boundaries (HAGBs). Additional STEM-EDX analyses were conducted at $200 \mathrm{kV}$ using an FEI Titan G2 80-200 aberration-corrected S/TEM with an X-FEG and ChemSTEM ${ }^{\mathrm{TM}}$ technology that uses four SDDs for improved $\mathrm{x}$-ray collection and EDX spectrum imaging and analysis.

\section{Results}

\section{$\underline{\text { Baseline material characterization }}$}

Several Alloy 600SA specimens were examined in the FEG-SEM using the BSE imaging mode in order to characterize the microstructure, to confirm the absence of surface scratches that might still be present after the polishing procedure, to assess any grain boundary tortuosity, and to confirm the absence of any intergranular oxide prior to exposure. A representative image of Alloy 600SA microstructure is presented in Figure 1.

Detailed SEM examination revealed that the material was characterized by coarse equiaxed grains ranging from 50 to $400 \mu \mathrm{m}(\sim 260 \pm 20 \mu \mathrm{m}$ average grain size $)$ and numerous annealing twins; this is consistent with the relatively high annealing temperature that has been used $\left(1100{ }^{\circ} \mathrm{C}\right)$. Higher magnification analysis of the same specimens with secondary electrons (SE) and BSE imaging modes revealed the presence of fine, discrete, darkly-imaging features 
along HAGBs, which were subsequently identified via TEM/electron diffraction/STEM-EDX analysis as Cr-rich $\mathrm{M}_{23} \mathrm{C}_{6}$ carbides. These precipitates are clearly visible in Figure 2(a) and (b).

Several HAGBs were cross-sectioned using the FIB and imaged in SE mode. Every GB imaged appeared straight in cross-section with no localized deviation from its original plane. Furthermore, no preferential etching of the grain boundaries was detected, thus confirming the successful polishing procedures with colloidal silica solution. Moreover, it was possible to confirm the absence of any intergranular oxide before the exposure from the SE images. A representative micrograph of the HAGB cross-section prior to oxidation is shown in Figure 3.

Further analyses of the Alloy 600SA specimens were performed using TEM. The microstructure of this material, shown in Figure 4, was characterised by the presence of a recrystallized microstructure with occasional dislocation pile-ups in the vicinity of grain boundaries and dicrete precipitates at the grain boundaries. The dislocations formed during the water-quench after the solution-anneal due to the steep thermal gradients developed during the quench that can introduce large stresses and local strain in the metal. The fine ( $\mathrm{x} \mathrm{nm}$ in size) intergranular precipitates were identified as semi-coherent $\mathrm{M}_{23} \mathrm{C}_{6}$ carbides using selected area electron diffraction (SAD) and dark-field TEM (Figure 4(c)). STEM-EDX microanalysis confirmed that these carbides were Cr-rich (Figure 5). It is important to note that carbide precipitation in Alloy 600 is never fully suppressed despite the water-quench. Furthermore, STEM-EDX (Figure 5) analysis indicated that the extent of Cr depletion observed at the high-angle grain boundaries (HAGBs) in the vicinity of the fine $\mathrm{M}_{23} \mathrm{C}_{6}$ carbides is narrow $(\sim 10 \mathrm{~nm})$. 
The appearance of the oxidized surface after exposure in $\mathrm{H}_{2}$-steam at $480{ }^{\circ} \mathrm{C}$ was similar for all the tested specimens. Representative SE and BSE images of oxidized HAGBs after $120 \mathrm{~h}$ are shown in Figure 6. The SE images of the oxidized Alloy 600 specimens revealed the presence of homogeneously-distributed intragranular features ("nodules") and a banded grain boundary structure, which appeared to protrude from the surface, forming ridges on the specimen surface. The surface "nodules" have been extensively studied in the past [16$18,25]$ and were found to be metallic Ni based on EDX analyses. In addition, BSE imaging of the same surface clearly showed the trace outline of the grain boundary and a bright region on either side of the grain boundary as well as a marked "protruded" GB region, as shown in Figure 6(b). The only differences observed between the 3 tests were the proportion of intragranular "nodules" and the extent of the protruded GB region, both of which increased with the exposure time.

High resolution SEM characterisation of the banded oxide structure at the grain boundaries revealed that the majority of HAGBs deviated from their original straight plane (Figure 7 (a) and (b)), and became very "wavy" after the exposure in $\mathrm{H}_{2}$-steam (Figure 7 (a)). The GB "line" was characterized by an undulating appearance in contrast to the straight "lines" previously observed in the characterisation of the as-solution-annealed and quenched samples (Figure 2). The "wavy" GB appearance observed after the exposure in $\mathrm{H}_{2}$-steam was similar to the faceted or bulged one that has been observed and described in several alloys that are susceptible to grain boundary migration [26,27], and will be discussed later in terms of diffusion-induced grain boundary migration (DIGM). However, from the surface analysis it was not possible to identify if the boundaries were migrating monolithically in a single direction into one grain, or they were migrating in both directions, alternatively migrating into each grains. 
From the representative $5 \mathrm{kV}$ SEM-BSE image of the undulating GB shown in Figure 7 (b), it was possible to identify a wavy darkly-imaging line, which is indicative of a feature with lower average atomic number in comparison to the alloy matrix; this linear feature followed the GB "waves", suggesting the presence of an intergranular oxide along the tortuous bowed GB.

In order to observe the preferential intergranular oxidation evolution as a function of exposure time, several HAGBs were cross-sectioned using the FIB technique and imaged using electron-beam SE imaging mode in the dual beam FIB. After 15 hours of exposure the HAGBs analysed were characterised by the presence of a darkly-imaging external oxide layer as well as some discrete internal oxide particles (Figure 8). From higher magnification examination it was also possible to observe an embryo of intergranular oxide. Moreover, the SE images reported in Figure 8 highlighted that the HAGB intersecting the surface appeared to be slightly "bowed" with the right grain protruding into the left grain for more than 100 $\mathrm{nm}$.

The same specimen was then re-exposed in the same high-temperature $\mathrm{H}_{2}$-steam environment for additional 20 hours. Figure 9 contains the FIB electron beam SE images of the same HAGB previously analyzed, but $5 \mu \mathrm{m}$ away from the previous cross-section. The main reason to prepare the second cross-section away from the previous one was to avoid any $\mathrm{Ga}^{+}$ ion contamination and implantation, which could have an effect on the oxidation behavior of Alloy 600SA. As evident in Figure 9, the depth of the intergranular oxide penetration was markedly increased after the second exposure. The intergranular oxide had grown past the 
previous GB bowed region. From more detailed observations, it was also possible to identify the presence of a new migrated region ahead the intergranular oxide.

From the HAGB FIB cross-section analysis of the first two short exposures, it was speculated that there might be limited GB migration in the near-surface region, possibly associated with the preferential intergranular oxidation of Alloy 600SA during high temperature exposure in $\mathrm{H}_{2}$-steam environment. However, it was also possible that this localized apparent migration could be related to the thermal exposure at $480{ }^{\circ} \mathrm{C}$.

To determine whether this effect was due to the $480{ }^{\circ} \mathrm{C}$ thermal treatment or due to preferential intergranular oxidation, two new specimens were exposed for 120 hours to determine the factor responsible for the apparent migration: one specimen was exposed in

pure $\mathrm{H}_{2}$, and a second specimen was exposed in the $\mathrm{H}_{2}$-steam environment. SEM characterisation of the 2 specimens after the exposure revealed a marked difference as evident in the SE images in Figure 10. As described previously, the Alloy 600 SA specimen exposed in the $\mathrm{H}_{2}$-steam environment (10 (a)) was characterized by the presence of "wavy" grain boundaries, suggesting the possible occurrence of GB migration, whereas the Alloy 600 SA specimen exposed to pure $\mathrm{H}_{2}$ environment did not show such "wavy"/undulating HAGBs (Figure $10(\mathrm{~b})$ ). These results strongly support that the apparent migration is associated with and most likely caused by the preferential intergranular oxidation occurring during high temperature $\mathrm{H}_{2}$-steam environment exposure.

TEM analysis of FIB Cross-Section Specimens

TEM characterisation of 5 electron-transparent FIB-prepared cross-section specimens that each contained at least one grain boundary was performed to analyse in detail the "bowed" 
boundary structures that appeared to be the result of migration during exposure in the $\mathrm{H}_{2}$ steam environment. The bright-field TEM image in Figure 11 shows a locally "bowed" GB in the near-surface region; the strongly diffracting grain (left grain) appeared to protrude into the adjacent grain (right grain).

Additional TEM analysis of the near-surface region revealed the presence of fine $(\sim 50 \mathrm{~nm})$ discrete precipitates "within" the grain, $\sim 300 \mathrm{~nm}$ from the "bowed" grain boundary (Figure 12 (b)). Selected area electron diffraction (SAD) analysis confirmed that these precipitates were face-centered cubic (fcc) $\mathrm{M}_{23} \mathrm{C}_{6}$ carbides. Dark-field TEM images showed that these carbides were aligned with the non-bowed (straight) portion of the GB. Further analysis revealed that other fine discrete $\mathrm{M}_{23} \mathrm{C}_{6}$ carbides were present along the "straight" portion of the same grain boundary. This provided unequivocal evidence that the $\mathrm{M}_{23} \mathrm{C}_{6}$ carbides were present along the original GB prior to the $\mathrm{H}_{2}$-steam exposure (Figure 12 (b)), and served as "markers" to identify the original GB position before migration.

Several grain high-angle boundaries, which exhibited a locally "bowed" morphology, were subsequently analysed using advanced analytical transmission electron microscopy. A series of Titan "ChemiSTEM" STEM-EDX SDD spectrum images are shown in Figure 13. The EDX analyses confirmed that the darkly-imaging surface layer was mainly composed of Crrich and Fe-rich oxides as shown in the $\mathrm{O} \mathrm{K} \alpha, \mathrm{Cr} \mathrm{K} \alpha$ (blue) and $\mathrm{Fe} \mathrm{K} \alpha$ (red) EDX spectrum images. Although the oxide layer appeared to be continuous, it did not protect the GB from further intergranular oxidation. In fact, an embryo of $\mathrm{Cr}$-rich intergranular oxide was detected along the path of the migrated GB suggesting that the superficial layer was insufficient to protect the GB. The pronounced $\mathrm{Cr}$ and $\mathrm{Fe}$ depletions and significant $\mathrm{Ni}$ enrichment was observed just beneath the surface oxide layer, as shown in the Ni Ka (green) spectrum image which also confirmed that the GB ridges were mainly composed of pure 
metallic Ni. The migrated GB region located beneath the surface oxide ridge was characterised by significant $\mathrm{Cr}$ and Fe depletion. Discrete FEG-STEM-EDX "spot” analyses were performed to measure the composition of these "migrated" regions. These STEM-EDX analyses confirmed that the entire migrated GB region was strongly depleted in $\mathrm{Cr}$ (to $\sim 4 \% \mathrm{wt}$ ) and $\mathrm{Fe}$ (to $\sim 2 \% \mathrm{wt}$ ) and was enriched in $\mathrm{Ni}$.

\section{Discussion}

The results of this study confirmed that solution-annealed Alloy 600 is susceptible to preferential intergranular oxidation in a high temperature $\mathrm{H}_{2}$-steam environment as previously postulated by Scenini et al. [16] and demonstrated by Bertali et al. [17].

The detailed SEM and TEM microstructural analyses performed in this study on solutionannealed Alloy 600 before and after exposure to the high-temperature $\mathrm{H}_{2}$-steam environment revealed distinct changes at the GBs both on the surface and beneath it, suggesting that HAGBs can be susceptible to migration in the near-surface region during the early stages of oxidation. In fact, after oxidation, a considerable number of high-angle grain boundaries were observed to have a wavy/undulating appearance, with migrations on the order of a few hundreds nanometres (Figure 7). Moreover, cross-sectional FIB/ATEM analyses of these boundaries revealed noticeable bowed regions at the GB just beneath the surface with one grain growing in to the other for more than $400 \mathrm{~nm}$ (Figure 11). It is therefore speculated that the occurrence of GB migration during Alloy 600 oxidation plays a significant role in the GB intergranular oxidation susceptibility and IGSCC.

It might be argued that GB migration might have been the result of the thermal exposure at $480{ }^{\circ} \mathrm{C}$. However, the microstructural analyses of the solution-annealed Alloy 600 after 
exposure in high-temperature $\mathrm{H}_{2}$ environment confirmed that HAGBs do not undergo migration in that environment at $480{ }^{\circ} \mathrm{C}$, as shown in Figure 10 . The possibility that GBs undergo migration during the solution-annealing treatment is also not supported by the observation of discrete $\mathrm{M}_{23} \mathrm{C}_{6}$ carbides on the grain boundaries. In fact, the observation of the intergranular $\mathrm{M}_{23} \mathrm{C}_{6}$ carbides along the path of the original boundaries clearly confirmed that the migration process occurred during oxidation in high-temperature $\mathrm{H}_{2}$-steam.

STEM-EDX microanalysis revealed that the GBs characterized by a migrated region consistently exhibited a zone ( $200 \mathrm{~nm}$ on either side of the GB) where the surface Cr-rich oxide had formed. The formation of this surface oxide may be due to the fast $\mathrm{Cr}$ diffusion along the boundary to the surface. Once this oxide is formed, the subsurface GB region can become strongly depleted in $\mathrm{Cr}$ (down to $\sim 5 \mathrm{wt} \%$ ) resulting in localised compositional variations and creating a compositional gradient from the martix to the depleted GB. Such $\mathrm{Cr}$ depletion and related GB migration might also be associated with localized Ni enrichment that is not "extruded" on the outer surface of the GBs to form Ni nodules. The direction of migration also appears to be dependent on the orientation of the grain boundary with respect to the intersecting metal/environment interface. Specifically, the grain boundary migrated towards the shallower grain, presumably because they are more easily $\mathrm{Cr}$ depleted following the formation of an external $\mathrm{Cr}$ rich oxide. The $\mathrm{Cr}$ diffusion along the $\mathrm{GB}$ to the surface and the presence of a compositional gradient may be the driving forces for the occurrence of GB migration. There is, in fact, clear experimental evidence that grain boundaries can be induced to migrate under certain conditions when solute atoms diffuse along them $[27,28]$. This process, which is termed "diffusion-induced grain boundary migration" (DIGM), is based on the observation that when solute atoms $(\mathrm{Cr})$ diffuse out of a boundary to some sinks, which in the present case is the surface oxide, the boundary is observed to migrate laterally, leaving 
behind a solute-depleted region. The evidence from the STEM-EDX microanalyses that the migrated region is markedly depleted in solute elements ( $\mathrm{Cr}$ and $\mathrm{Fe}$ ) (Figure 13) indicates that DIGM occurred during $480^{\circ} \mathrm{C}$ oxidation of Alloy 600. A similar solute element depletion adjacent to a migrated boundary have been also observed by Stott and Shida $[29,30]$ on internally oxidized Ni-Al alloys. They suggested that the extensive internal and intergranular oxidation was leading to compressive stresses causing the formation of an internal-oxide denuded zone aside the GBs. However, in the present case, the formation of a Cr-rich superficial oxide above HAGBs protected the bulk material in proximity of the grain boundary from internal oxidation and ,therefore, the local compressive stress at the grain boundary is likely to decrease. In fact, residual stress measurements carried out with FIB micro-hole drilling technique on Alloy 600 oxidized in $\mathrm{H}_{2}$-steam has shown that residual stresses were highly compressive in the bulk of the grains $(-300 \mathrm{MPa})$ where internal oxidation occurred, and markedly reduced as the grain boundary was approached (-110 $\mathrm{MPa})$ [17]. Consequently, it seems reasonable to assume that the only possible driving force to cause GB migration is the compositional gradient present at the solute-depleted boundary in the near-surface region.

Once GB migration starts, the migrated $\mathrm{Cr}$ - and Fe-depleted region may be associated with a local volume change due to the differences of the fluxes and atomic dimension of solute and solvent atoms. This volume change could then be responsible for the generation of large compressive or tensile stresses in the depleted region [26]. This potentially stressed region can then induce/contribute to the fracture of the brittle Cr-rich oxide surface layer exposing the underneath Cr-depleted migrated GB to the environment. Finally, if the $\mathrm{Cr}$ level in the depleted region is too low for the formation of a protective oxide, no protective oxide would form and fast $\mathrm{O}$ diffusion could proceed deeper into the alloy, thus promoting further intergranular oxidation (Figure 7). Once an intergranular oxide is formed the incoherent 
metal/oxide interface might act as a preferential path for faster $\mathrm{O}$ diffusion causing more intergranular oxide penetration. The process can then be self-sustained, with repeated GB oxidation, migration and oxide cracking. This process might also become relevant for short crack propagation and evolve into the slip oxidation propagation model proposed by LozanoPerez et al. [9]. Moreover, the high stresses present in the migrated region might generate extrinsic grain boundary dislocations, which might enhance HAGBs migration. It is thought that the driving force for the occurrence of DIGM is the compositional gradient present at HAGBs, and that the mechanism by which migration occurs is the self-sustaining climb of grain boundary dislocations and motion of their associated grain boundary steps [27]. The generation of grain boundary dislocations could also locally enhance HAGB diffusivity by acting as preferential paths of atomic diffusion in a similar manner to the dislocation pipediffusion creep mechanism proposed by Guruswamy et al. [31]. This mechanism has also been proposed by Bertali et al. [17] and Persuad et al. [20] in order to explain the formation of pure metallic $\mathrm{Ni}$ nodules on the surface of Alloy 600 after exposure in $\mathrm{H}_{2}$-steam environment at high temperature and might explain, in the present case, the enhanced grain boundary $\mathrm{O}$ and $\mathrm{Cr}$ diffusivity. The fact that the localized compositional changes were observed mainly in the GB-migrated regions might suggest that diffusion in moving boundaries is faster than in stationary ones as observed in past studies by Hillert et al. [32] and Smidoda et al. [33]. Hillert observed that the chemical diffusion coefficient of $\mathrm{Zn}$ in $\alpha$ Fe in moving boundary was $10^{4}$ times higher than for stationary ones, while Smidoda deduced a similar behaviour for $\mathrm{Al}$ diffusivity in a deformed supersaturated $\mathrm{Ni}-\mathrm{Cr}$ - $\mathrm{Al}$ solid solution by observing the growth of $\mathrm{Ni}_{3} \mathrm{Al}$ precipitates behind the migrating recrystallization front. Interestingly, the discrepancy between extrapolated and measured $\mathrm{Cr}$ and $\mathrm{O}$ diffusion coefficients in Ni-based alloys at PWR relevant temperatures is in the same order of 
magnitude [4-9], thus suggesting that GB migration might be the mechanism by which boundary diffusivity is enhanced.

Although, the current experiments were conducted in $\mathrm{H}_{2}$-steam environment at $480{ }^{\circ} \mathrm{C}$, the marked $\mathrm{Cr}$ and $\mathrm{Fe}$ depletion detected in the migrated region was also observed on Alloy 600 tested in PWR simulated primary water [11] but on a much smaller scale $(9 \mathrm{~nm})$. Despite its small extent and the low importance given to it, the results reported herein strongly suggest that GB migration is an important factor in the early stages of oxidation and IGSCC incubation. It is also believed that this phenomenon might also play an important role in Alloy 690 oxidation and stress corrosion cracking because GB migration and localized solute depletions have also been reported for Alloy 690 in PWR primary water [15].

It is also note-worthy that in the 1980's [34-36], thermally-treated Alloy 600 was introduced as a replacement for mill-annealed Alloy 600 in order to minimize/reduce the material's susceptibility to SCC in primary water environments. The extensive intergranular precipitation of $\mathrm{Cr}$-rich $\mathrm{M}_{7} \mathrm{C}_{3}$ was shown to be beneficial. The presence of such coarse intergranular carbides would make it difficult for a grain boundary to migrate at lower temperatures, as these carbides would effectively "pin" the grain boundaries. Thus, the results reported in this investigation support the "apparent" beneficial effect of thermaltreatment of Alloy 600 to reduced susceptibility to SCC in primary water environments.

\section{Conclusions}

1. Surface oxidation of strain-free solution-annealed Alloy 600 tested in low pressure $\mathrm{H}_{2}$-steam at $480^{\circ} \mathrm{C}$ was characterised by the formation of fine, discrete internal $\mathrm{Cr}$ rich oxides and Cr-rich intergranular oxide. 
2. It was conclusively demonstrated that GB migration and the formation of the associated Cr- and Fe-depleted region occurred at high-angle grain boundaries in the near-surface region in the presence of $\mathrm{H}_{2}$-steam environment at $480{ }^{\circ} \mathrm{C}$.

3. Preferential intergranular oxide penetration was observed to occur along the newly migrated and solute-depleted grain boundary instead of along the original boundary position.

4. The relationship between preferential intergranular oxidation and grain boundary migration in the initiation of PWSCC requires further study, and might provide a better understanding of the initiation mechanism responsible for PWSCC.

Acknowledgements

The authors thanks AREVA for support. Funding for the aberration-corrected FEI Titan G2 80-200 200S/TEM and the associated research capability of the Nuclear Advanced Manufacturing Research Centre at the School of Materials, University of Manchester, Manchester UK was provided by HM Government (UK).

\section{References}

1. P.M. Scott, M. Le Calvar, "Some Possible Mechanisms of Intergranular Stress Corrosion Cracking of Alloy 600 in PWR Primary Water", In: Proceedings of the $6^{\text {th }}$ international symposium on environmental degradation of materials in nuclear power system- water reactors, minerals, metals and material society/AIME (1993), 657-670.

2. P.L Andresen, R. Reid and J. Wilson, "SCC Mitigation of Ni Alloys and Weld Metals by Optimizing Dissolved H2." In: Proceedings of the $14^{\text {th }}$ international symposium on environmental degradation of materials in nuclear power system-water reactors, mineral, metals and materials society/AIME (2009), 345-372. 
3. Y. Qiu, T. Shoji and Z. Lu, "Effect of Dissolved Hydrogen on the Electrochemical Behaviour of Alloy 600 in Simulated PWR Primary Water at $290^{\circ}$ C.", Corrosion Science, 53 (2011), 1983-1989.

4. D.A. Woodford, R.H. Bricknell, "Embrittlement of High Temperature Alloys by Oxygen.”, Treatise on Materials Science \& Technology, 25 (1982), 157-199.

5. R.G. Iacocca, D.A. Woodford, "The Kinetics of Intergranular Oxygen Penetration in Nickel and its Relevance to Weldment Cracking." Metallurgical and Materials Transactions A, 19A (1988), 2305-2313.

6. P. Scott, "Mechanism of Intergranular Cracking in Nickel Alloy Components of PWRs." Mechanism of Material Degradation and Non-destructive Evaluation in Light Water Reactors (2002), 107-118.

7. R.W. Staehle, Z. Fang, "Comments on a Proposed Mechanism of Internal Oxidation for Alloy 600 as Applied to low Potential SCC." In: Proceedings of the $9^{\text {th }}$ international symposium on environmental degradation of materials in nuclear power system-water reactors, mineral, metals and materials society/AIME (2000), 107.

8. K. Fujii, K. Fukuya, N. Nakajima, "Studies on Mechanism Elucidation by Direct Observation of Crack Tips.", Mechanism of Material Degradation and Nondestructive Evaluation in Light Water Reactors (2002), 165-178.

9. S. Lozano-Perez, J.M Titchmarsh, "TEM Investigations of Intergranular Stress Corrosion Cracking in Austenitic alloys in PWR Environmental Conditions.”, Materials at High Temperatures, 20(4) (2003), 573-579.

10. J. Panter, B. Viguier, J-M Cloue, M. Foucault, P. Combrade and E. Andrieu, "Influence of Oxide Films on Primary Water Stress Corrosion Cracking Initiation of Alloy 600.” Journal of Nuclear Materials, 348 (2006), 213-221. 
11. D.K. Schreiber, M.J. Olszta, D.W. Saxey, K. Kruska, K.L. Moore, S. Lozano-Perez, S.M. Bruemmer, "Examinations of Oxidation and Sulfidation of Grain Boundaries in Alloy 600 Exposed to Simulated Pressurized Water Reactor Primary Water.", Microscopy \& Microanalysis, 19 (2013), 676-687.

12. M. Sennour, P. Laghoutaris, C. Guerre, R. Molins, “ Advanced TEM Characterization of Stress Corrosion Cracking of Alloy 600 in Pressurized Water Reactor Primary Water Environment.”, Journal of Nuclear Materials, 393 (2009), 254-266.

13. L.E. Thomas, S.M. Bruemmer, "High-resolution Characterization of Intergranular Attack and Stress Corrosion Cracking of Alloy 600 in High-Temperature Primary Water.", Corrosion, 55(6) (2000), 572-587.

14. R.C. Newman, T.S. Gendron, P.M. Scott, "Internal Oxidation and Embrittlement of Alloy 600.”, In: Proceedings of the $9^{\text {th }}$ international symposium on environmental degradation of materials in nuclear power system-water reactors, mineral, metals and materials society/AIME (2000), 79-93.

15. M.J. Olszta, D.K. Schreiber, M.B. Toloczko, S.M Bruemmer, “Alloy 690 Surface Nanostructures During Exposure to PWR Primary Water and Potential Influence on Stress Corrosion Cracking Initiation.”, In: Proceedings of the $16^{\text {th }}$ international symposium on environmental degradation of materials in nuclear power system-water reactors, minerals, metals and materials society/AIME (2013).

16. F. Scenini, Roger C. Newman, Robert A. Cottis, Richard J. Jacko. "Alloy 600 Oxidation Studies Related to PWSCC.”, In: Proceedings of the $12^{\text {th }}$ international symposium on environmental degradation of materials in nuclear power system-water reactors, minerals, metals and materials society/AIME (2005), 891-902.

17. G. Bertali, F. Scenini, J. Lindsay, B. Winiarski, X. li Zhong, M. G. Burke, “Oxidation Studies of Alloy 600 in Low Pressure Hydrogenated Steam.”, In: Proceedings of the 
$16^{\text {th }}$ international symposium on environmental degradation of materials in nuclear power system-water reactors, minerals, metals and materials society/AIME (2013).

18. J. Lindsay, F. Scenini, X. Zhou, G. Bertali, Robert A. Cottis, M.G. Burke, F. Carrette, F. Vaillant; "Characterisation of Stress Corrosion Cracking and Internal Oxidation of Alloy 600 in High Temperature Hydrogenated Steam", In: Proceedings of the $16^{\text {th }}$ international symposium on environmental degradation of materials in nuclear power system-water reactors, minerals, metals and materials society/AIME (2013).

19. G. Economy, R.J. Jacko, F. W. Pement. "IGSCC Behavior of Alloy 600 Steam Generator Tubing in Water or Steam Tests Above $360{ }^{\circ}$ C.”, Corrosion, 43 (12) (1987), 727-734.

20. S.Y. Persaud, A. Korinek, J. Huang, G.A. Botton, R.C. Newman. "Internal Oxidation of Alloy 600 Exposed to Hydrogenated Steam and the Beneficial Effects of Thermal Treatment", Corrosion Science, 86 (2014), 108-122.

21. S.Y. Persaud, A. Korinek, R.C. Newman, "Internal Oxidation of Alloy 690 in Hydrogenated Steam.”, Corrosion Science, 90 (2015), 606-613.

22. Giannuzzi and F. A. Stevie, "Introduction to Focused Ion Beams: Instrumentation, Theory, Techniques and Practice.” Textbook, Springer, 2005.

23. Lozano-Perez, "A guide on FIB Preparation of Samples Containing Stress Corrosion Crack Tips for TEM and Atom-Probe Analysis.”, Micron., 39 (2008), 320-328.

24. F. Scenini, and A.H. Sherry, "SCC of Sensitized 304SS in High Temperature Water With Anionic Impurities Contamination.” Corrosion, 68 (2012), 1094-1107.

25. R.C. Newman, F. Scenini, "Another Way to Think About the Critical Oxide Volume Fraction for the Internal-to External Oxidation Transition?”, Corrosion, 64 (2008), $721-726$

26. A.H. King, "Diffusion Induced Grain Boundary Migration.”, International Materials Reviews, 32(4) (1987), 173-189.

27. R.W. Balluffi, J.W. Cahn, "Mechanism for Diffusion Induced Grain Boundary Migration.”, Acta Metallurgica, 29 (1980), 493-500. 
28. J.W Cahn, J.D. Pan, B.W. Balluffi, Scripta Metallurgica, (1978), 13:503.

29. F.H. Stott, Y. Shida, D.P. Whittle, G.C. Wood, B.D. Bastow, “The Morphological and Structural Development of Internal Oxides in Nickel-Aluminium Alloys at High Temperatures.”, Oxidation of Metals, 18 (1982), 127-146

30. Y. Shida, F.H. Stott, B.D. Bastow, D.P. Whittle, G.C. Wood, "Development of Preferential Intergranular Oxides in Nickel-Aluminium Alloys at High Temperatures." Oxidation of Metals, 18 (1982), 93-113.

31. S. Guruswamy, S.M Park, J.P. Hirth, R.A. Rapp, "Internal Oxidation of Ag-In Alloys: Stress Relief and the Influence of Imposed Strain.” Oxidation of Metals, 26 (1986), 77-100.

32. M. Hillert, G.R. Purdy, "Chemically Induced Grain Boundary Migration.”, Acta Metallurgica, 26 (1978), 333.

33. K. Smidoda, W. Gottschalk, H. Gleiter, "Diffusion in Migrating Interfaces." Acta Metallurgica, 26 (1978), 1833.

34. G. P. Airey, "Optimization of Metallurgical Variables to Improve the Stress Corrosion Resistance of Inconel 600.”, EPRI NP-3051 (Paolo Alto, CA: Electric Power Research Institute 1983).

35. N. Pessal, G. P. Airey, and B. P. Lingenfelter, "The Influence of Thermal Treatment on the SCC Behavior of Inconel Alloy 600 at Controlled Potentials in 10\% Caustic Soda Solutions at $315^{\circ} \mathrm{C}$." Corrosion, 35 (1979), 100-107.

36. G. Economy, R. J. Jacko, and F. W. Pement, "IGSCC Behavior of Alloy 600 Steam Generator Tubing in Water or Steam Tests Above $360^{\circ} \mathrm{C} "$, Corrosion, 43 (1987). 


\section{Tables}

\begin{tabular}{|l|l|l|l|l|l|l|l|l|l|l|}
\hline Heat No. & $\mathrm{C}$ & $\mathrm{Mn}$ & $\mathrm{S}$ & $\mathrm{P}$ & $\mathrm{Si}$ & $\mathrm{Cr}$ & $\mathrm{Ni}$ & $\mathrm{Cu}$ & $\mathrm{Co}$ & $\mathrm{Fe}$ \\
\hline 93510 & .047 & .23 & .002 & .005 & .30 & 15.42 & 74.43 & .01 & .057 & 8.94 \\
\hline
\end{tabular}

Table 1: Alloy 600SA composition (wt. \%)

\begin{tabular}{|c|c|c|c|c|c|c|c|}
\hline Test \# & Material & Time & $\begin{array}{c}\text { Ratio } \\
\text { steam//H2 }\end{array}$ & $\begin{array}{c}\text { Pressure } \mathrm{O}_{2} \\
\left(\mathbf{p O}_{2}\right)\end{array}$ & $\begin{array}{c}\text { Dissociation } \\
\text { pressure } \mathrm{Ni} / \mathrm{NiO} \\
{ }_{(\mathrm{pO} 2 \mathrm{Ni} / \mathrm{NiO})}\end{array}$ & $\begin{array}{c}\text { Ratio } \\
\left(\mathrm{pO}_{2} \mathrm{Ni} / \mathrm{NiO}\right) \\
/\left(\mathrm{pO}_{2}\right)\end{array}$ & Purpose \\
\hline & & $\mathrm{h}$ & & Atm & Atm & & \\
\hline 1 & $600 \mathrm{SA}$ & 15 & 62.16 & $9.88 \times 10^{-26}$ & $2.34 \times 10^{-24}$ & 23.70 & $\begin{array}{c}\text { Map oxidation } \\
\text { stages }\end{array}$ \\
\hline 2 & 600SA & 20 & 62.16 & $9.88 \times 10^{-26}$ & $2.34 \times 10^{-24}$ & 23.70 & $\begin{array}{c}\text { Map oxidation } \\
\text { stages }\end{array}$ \\
\hline 3 & $600 \mathrm{SA}$ & 120 & 62.16 & $9.88 \times 10^{-26}$ & $2.34 \times 10^{-24}$ & 23.70 & $\begin{array}{c}\text { Map oxidation } \\
\text { stages }\end{array}$ \\
\hline 4 & $600 \mathrm{SA}$ & 120 & N/A & N/A & $2.34 \times 10^{-24}$ & $\begin{array}{c}\text { Pure } \mathrm{H}_{2} \\
\text { environment }\end{array}$ & $\begin{array}{l}\text { Effect of } \mathrm{H}_{2} \text { on } \\
\text { the oxidation }\end{array}$ \\
\hline
\end{tabular}

Table 12: Summary of the experiments carried out in the $\mathrm{H}_{2}$-steam system. 


\section{Figures}

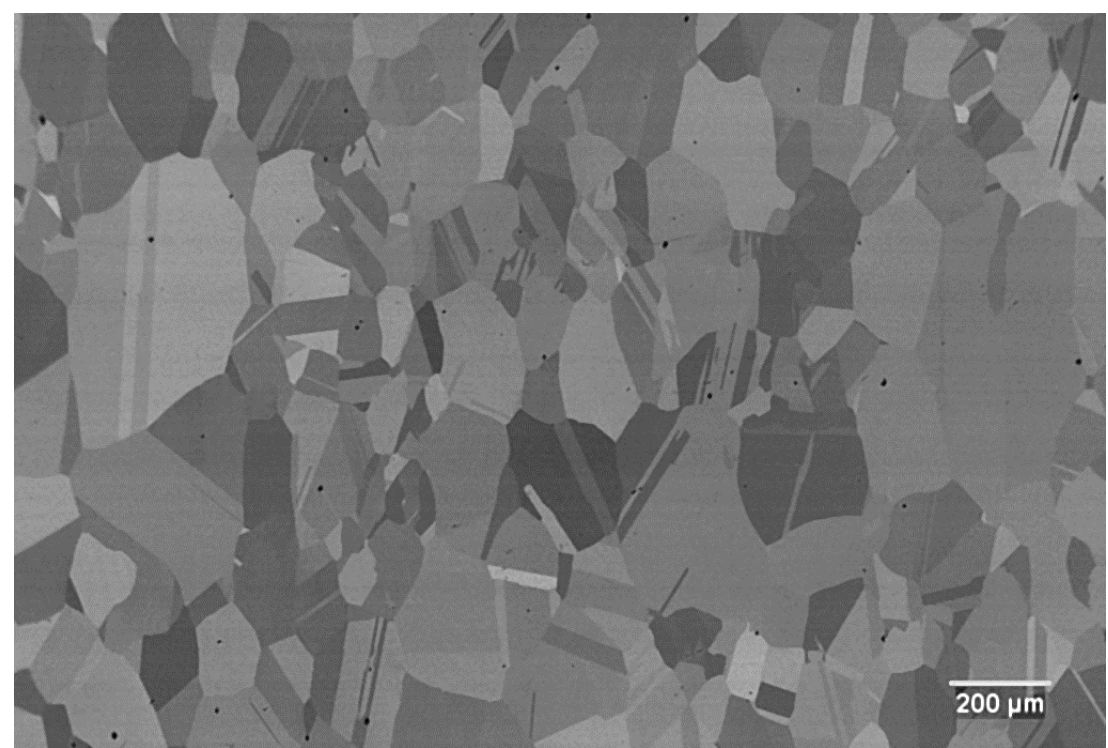

Figure 1: SEM BSE image of polished Solution annealed Alloy 600.

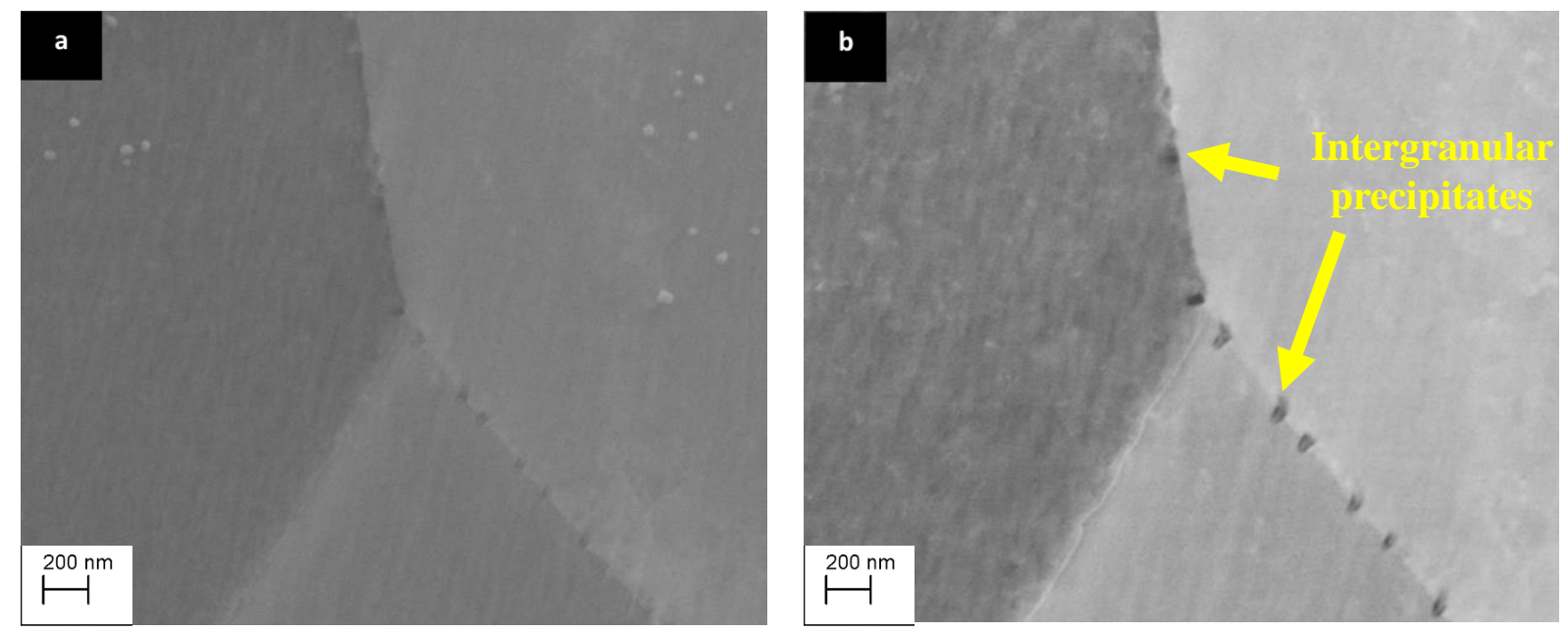

Figure 2: SEM SE (a) and BSE (b) images of the darkly-imaging precipitates along the HAGBs. 


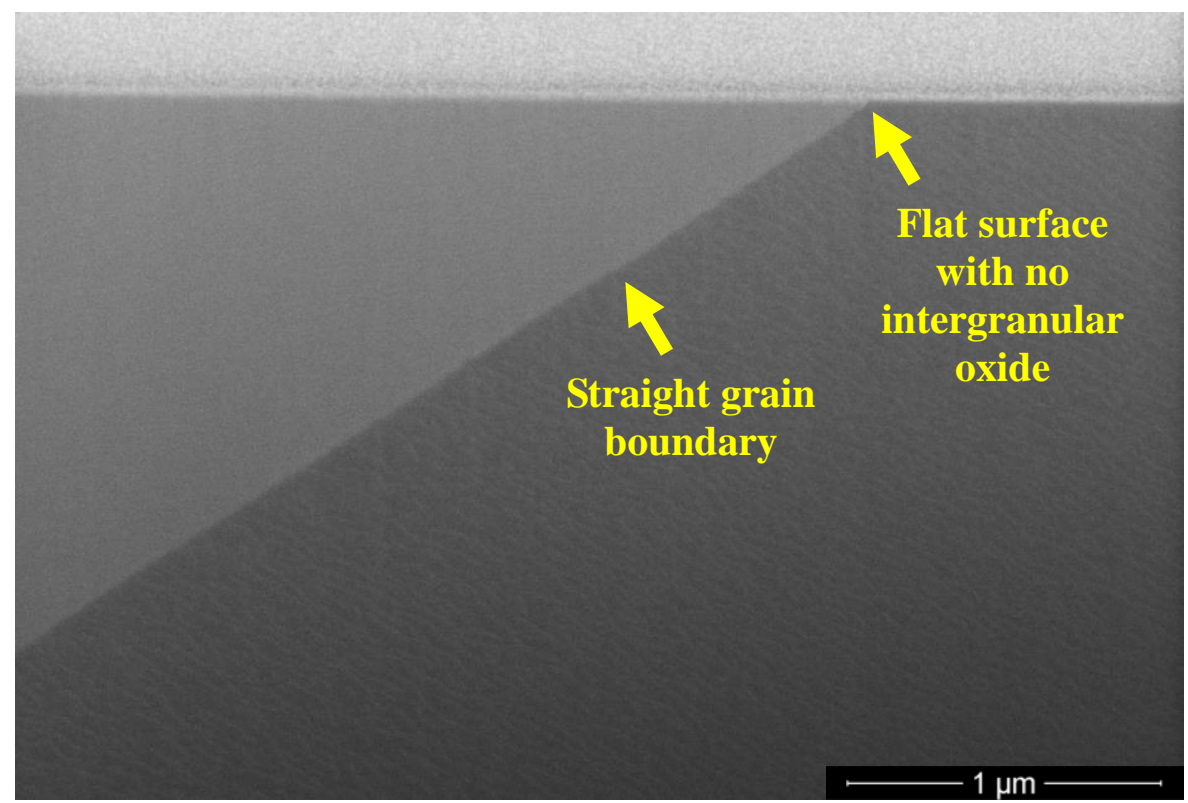

Figure 3: SEM SE image of an Alloy 600SA cross-section containing a high-angle grain boundary showing the absence of surface etching and GB tortuosity.

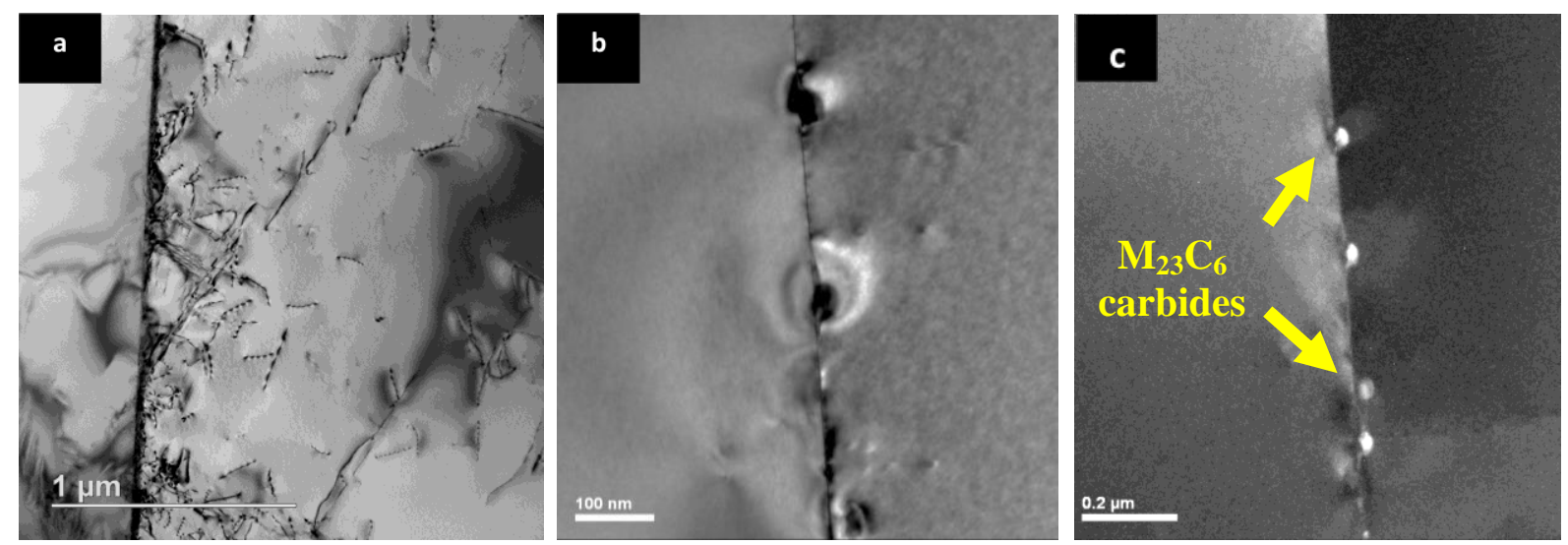

Figure 4: (a) TEM brightfield (BF) image of electropolished Alloy 600SA showing dislocation pile-up at the GB; TEM BF (b) and darkfield (c) images of Alloy 600SA showing the presence of intergranular $\mathrm{Cr}$-carbides, which were identified via electron diffraction as $\mathrm{M}_{23} \mathrm{C}_{6}$.
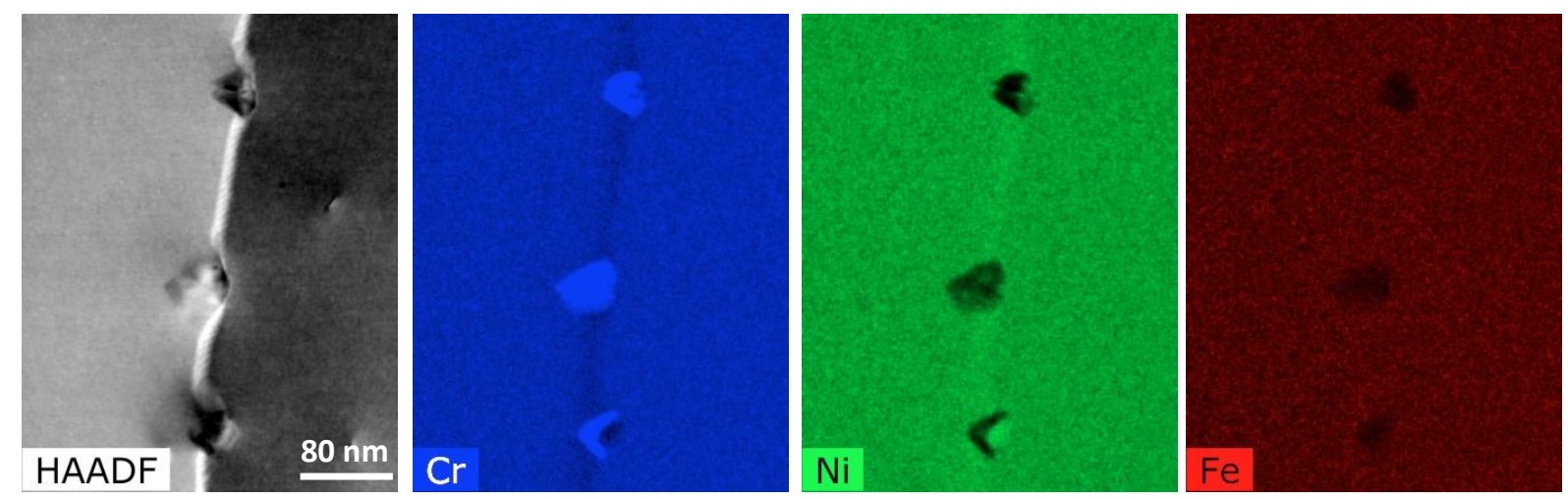

Figure 5: Titan STEM-HAADF image and corresponding SSD-EDX spectrum images of electropolished Alloy 600SA showing the Intergranular $\mathrm{Cr}$-rich $\mathrm{M}_{23} \mathrm{C}_{6}$ carbides and the extent of $\mathrm{GB} \mathrm{Cr}$-depletion before the exposure in $\mathrm{H}_{2}$-steam environment. 

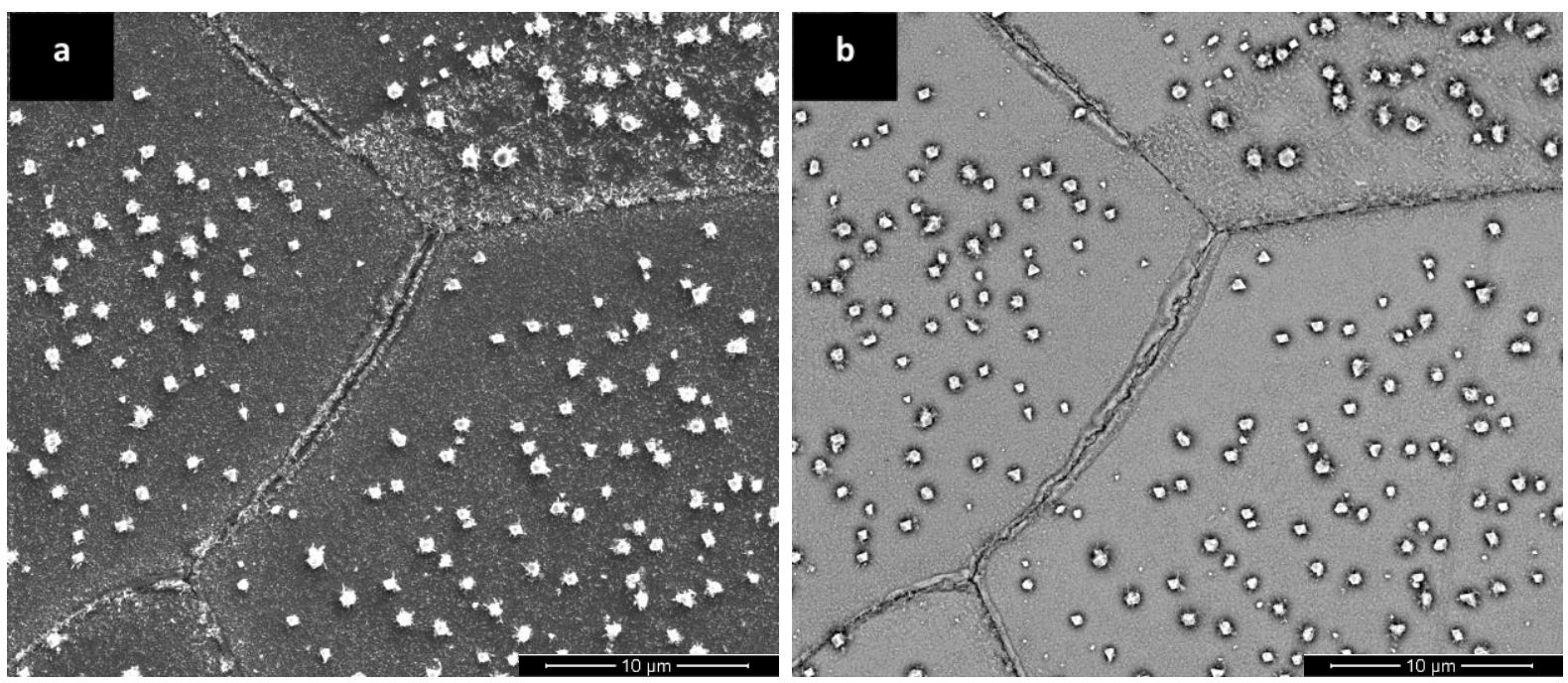

Figure 6: (a) SE and (b) BSE images of the oxidized surface morphology of Alloy 600SA specimen after 120 hours in $\mathrm{H}_{2}$-steam exposure at $480{ }^{\circ} \mathrm{C}$.
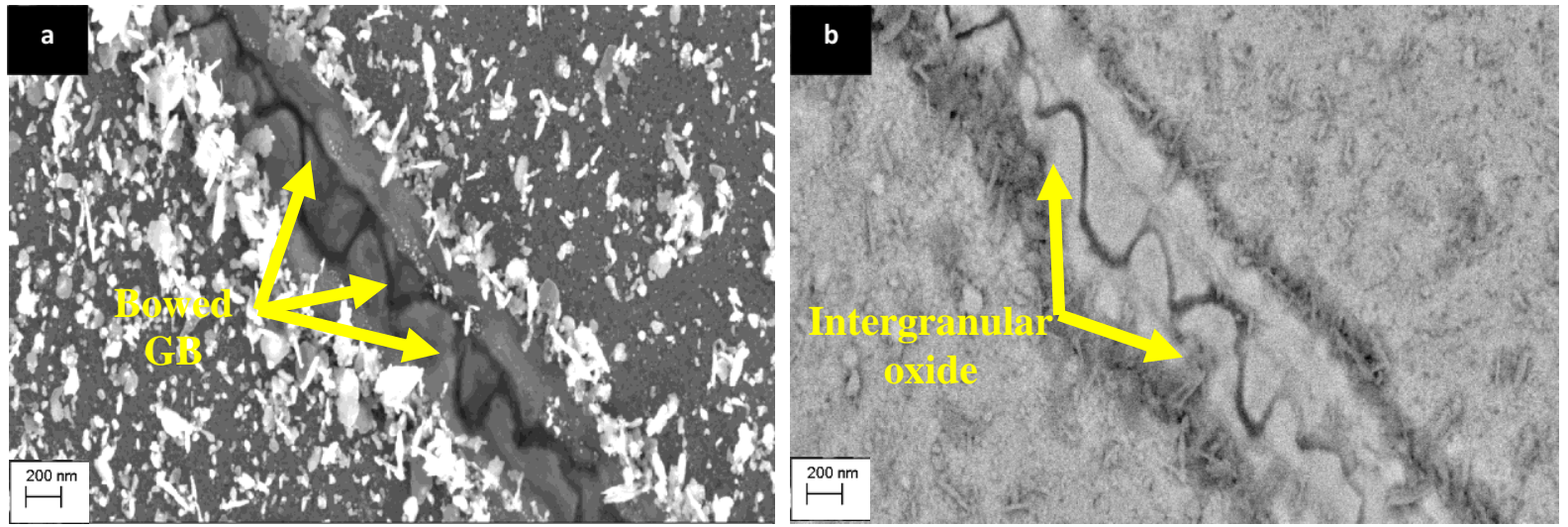

Figure 7: SE (a) and BSE (b) SEM images of an HAGB after 120 hours of exposure in $\mathrm{H}_{2}$-steam environment at $480^{\circ} \mathrm{C}$ showing the "bowed" grain boundary appearance.

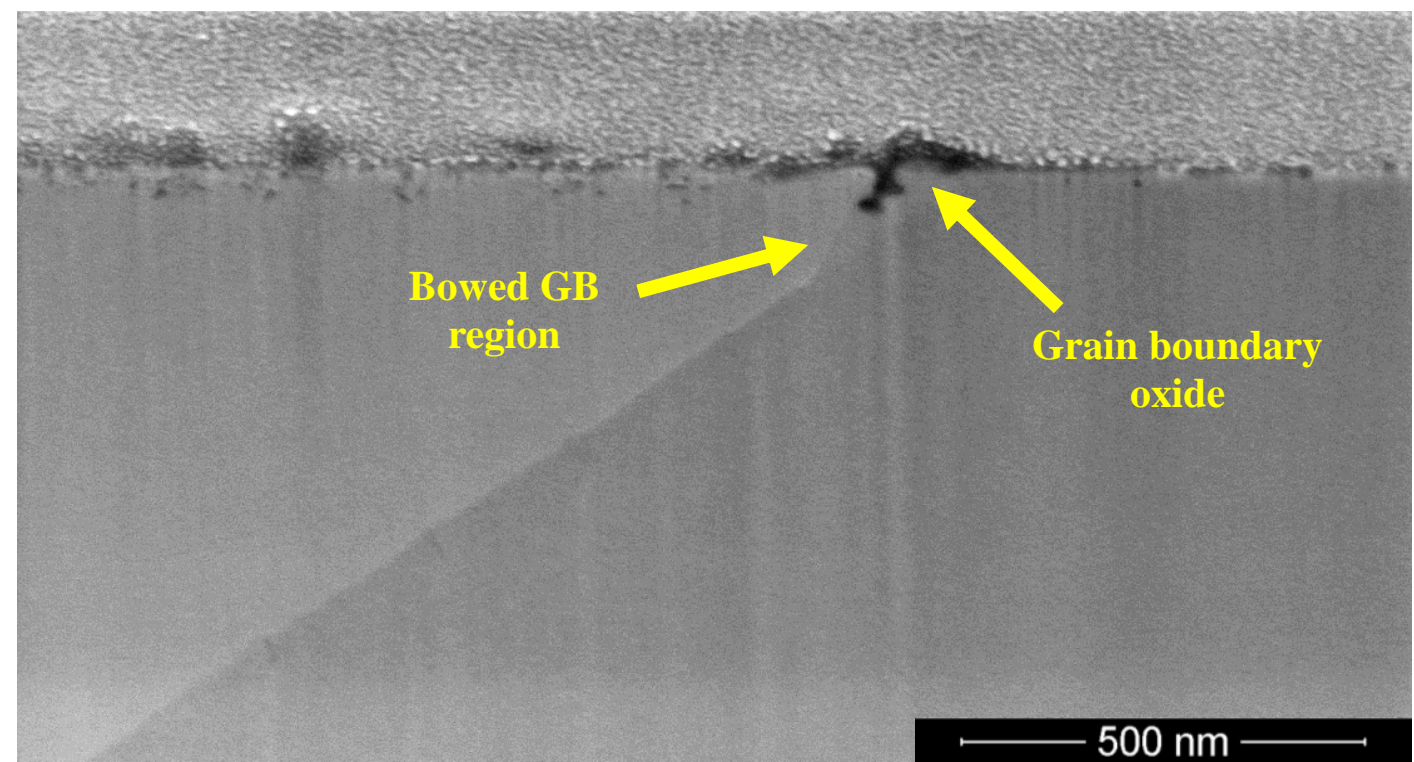

Figure 8: SE image of a cross-section obtained through an oxidized HAGB after 15 hours of exposure in $\mathrm{H}_{2^{-}}$ steam environment at $480{ }^{\circ} \mathrm{C}$. 


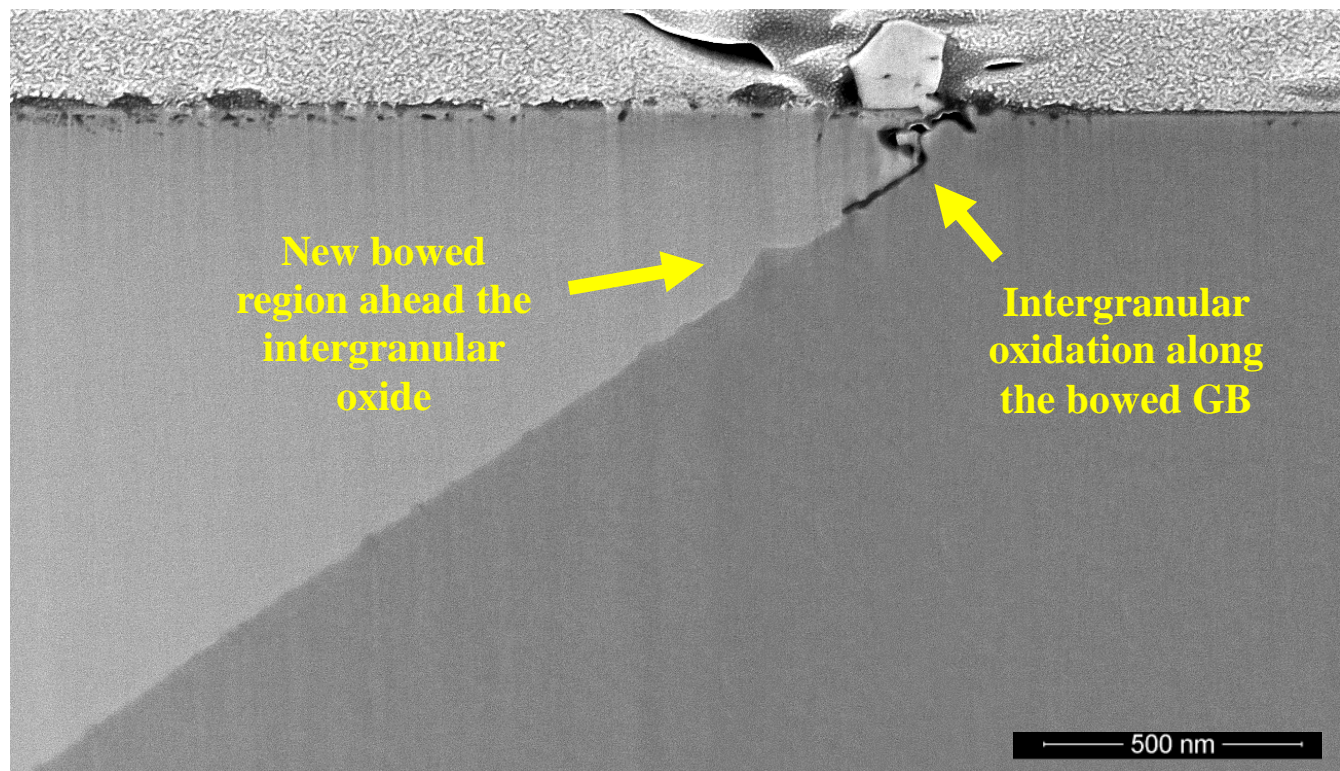

Figure 9: SE image of a cross-section obtained through an oxidized HAGB after 35 hours of exposure in $\mathrm{H}_{2}$ steam environment at $480{ }^{\circ} \mathrm{C}$.
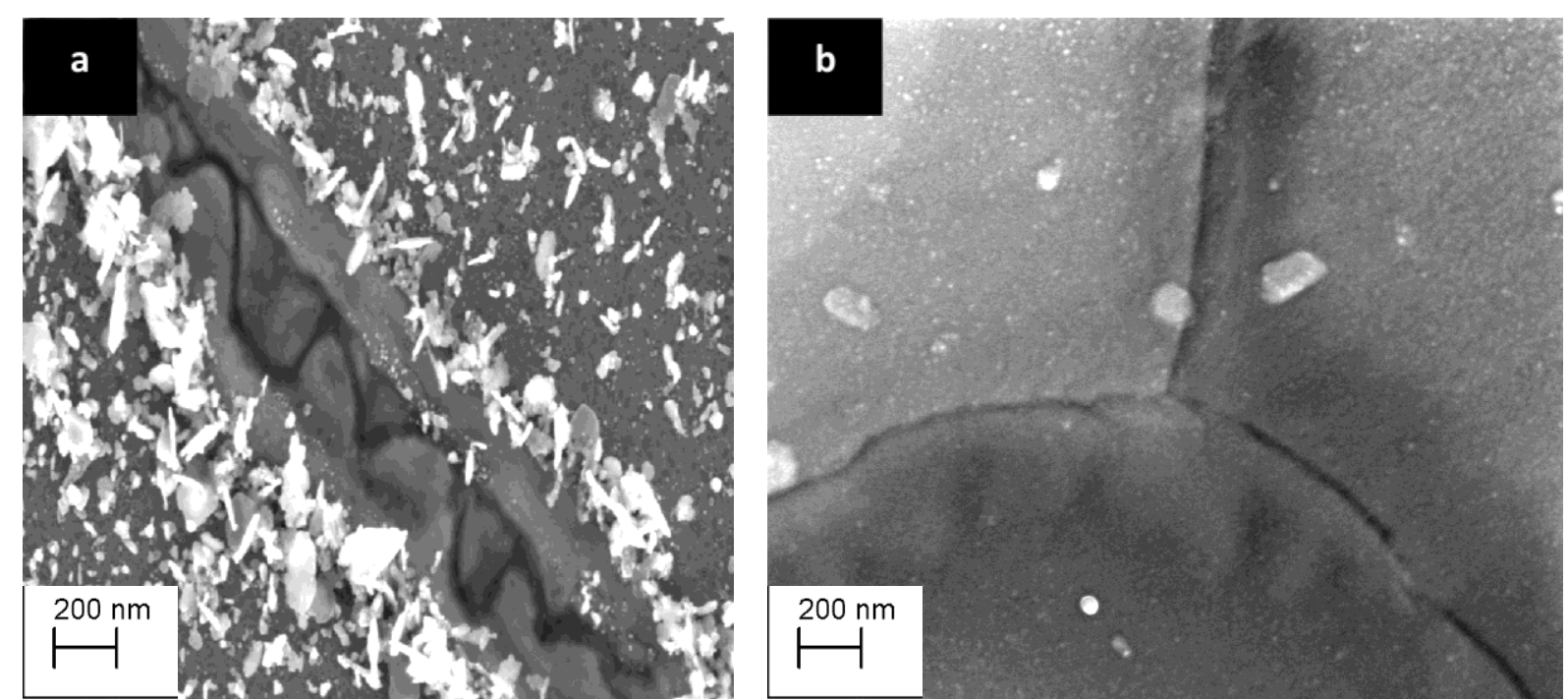

Figure 10: SE SEM images of HAGBs after 120 hours exposure at $480^{\circ} \mathrm{C}$ in $\mathrm{H}_{2}$-steam environment (a) and pure $\mathrm{H}_{2}$ environment (b). 


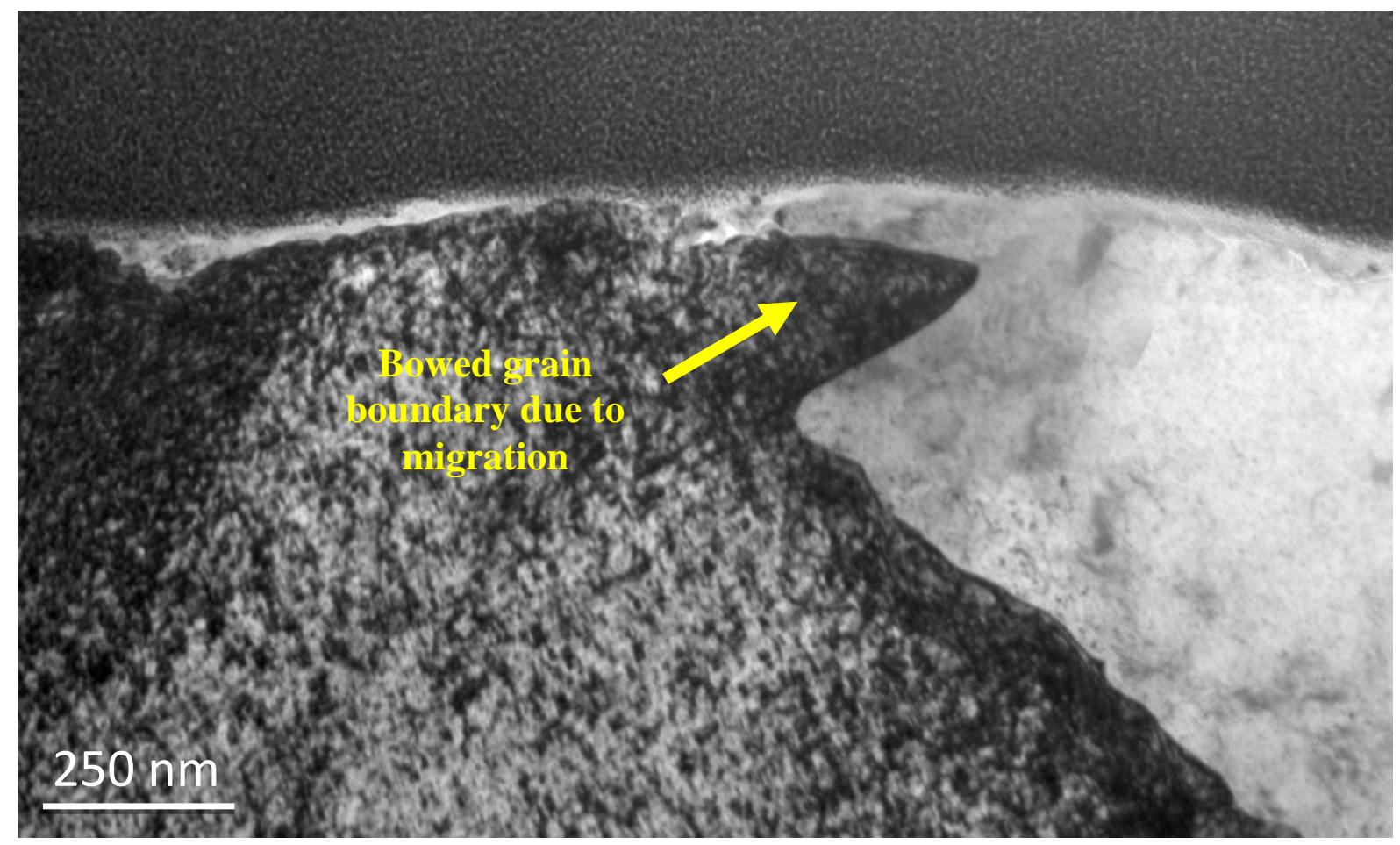

Figure 11: TEM bright-field (BF) images showing "bowed" grain boundary (left-grain is in contrast/strongly diffracting) after 120 hours exposure at $480{ }^{\circ} \mathrm{C}$ in $\mathrm{H}_{2}$-steam environment.
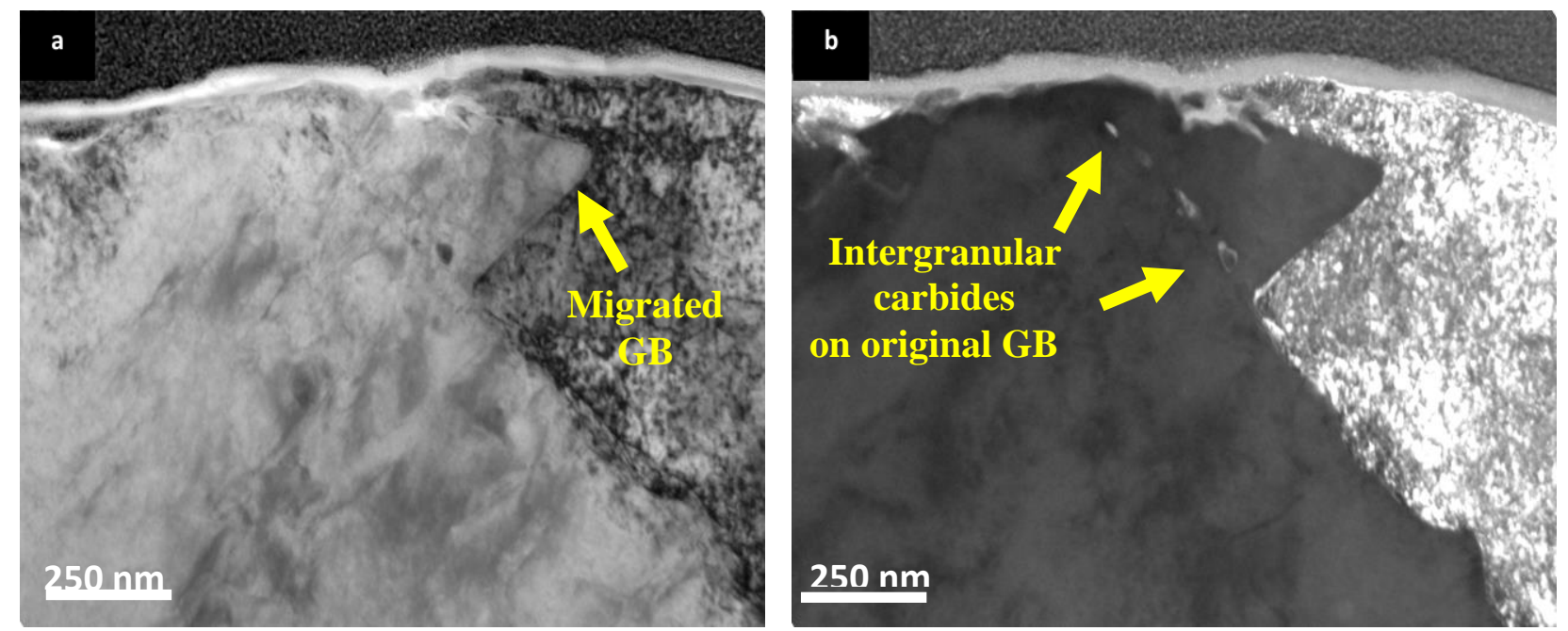

Figure 12: TEM BF (a) and DF (b) images show the "bowed" (migrated) region at the GB after 120 hours exposure at $480{ }^{\circ} \mathrm{C}$ in $\mathrm{H}_{2}$-steam environment.. The presence of intergranular $\mathrm{M}_{23} \mathrm{C}_{6}$ carbides along the path of the original GB confirmed the identification of the original GB position before migration. 

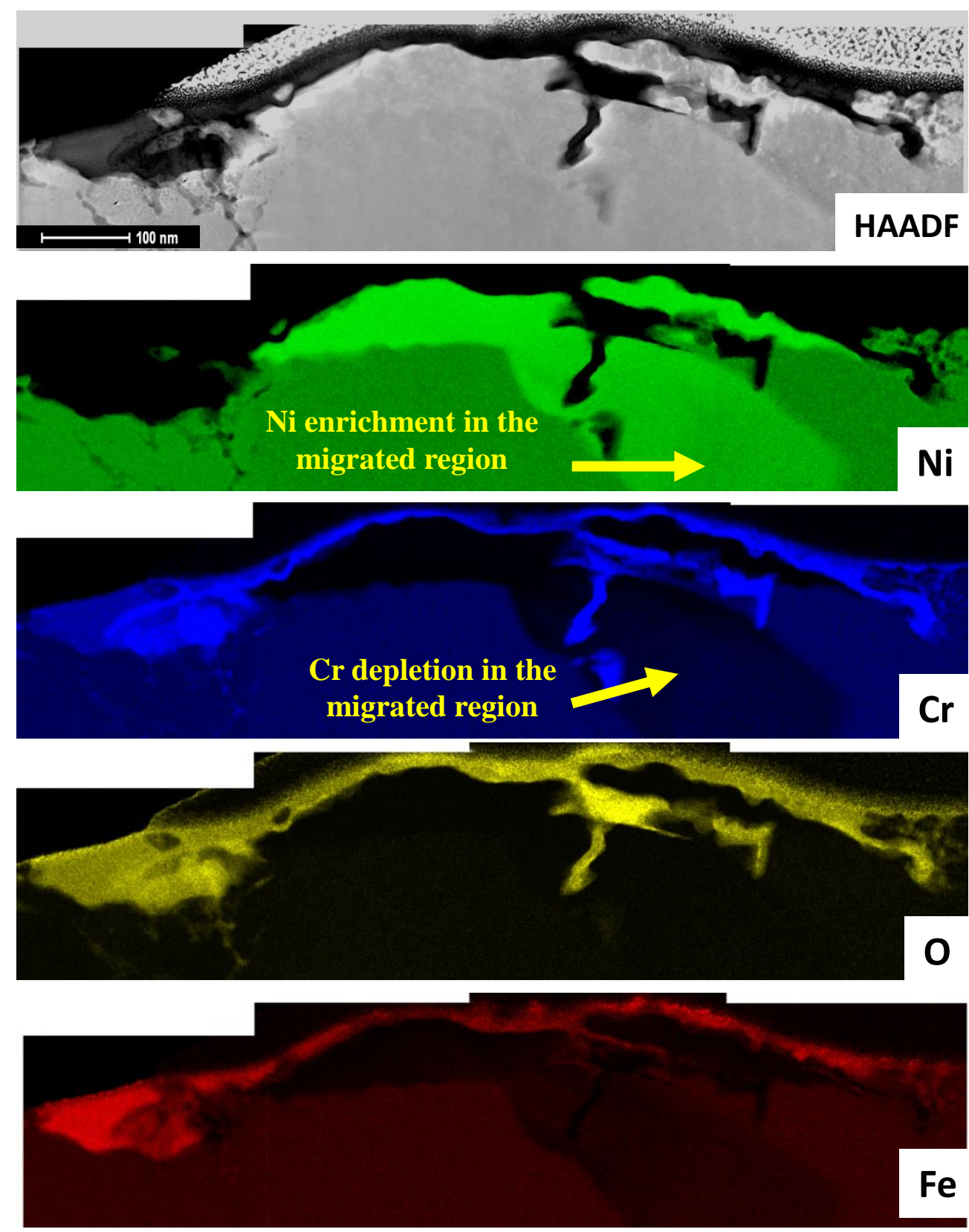

Figure 13: Titan STEM-HAADF image and corresponding SSD-EDX spectrum images of the migrated GB after 120 hours exposure at $480{ }^{\circ} \mathrm{C}$ in $\mathrm{H}_{2}$-steam environment., showing the presence of a surface $\mathrm{Cr}$-Fe-rich oxide above the GB. Pronounced $\mathrm{Cr}$ and $\mathrm{Fe}$ depletions associated with a marked Ni enrichment are visible below the oxide layer in the migrated region. 